\title{
MENILAI KESEHATAN KEUANGAN MITRA DALAM ANALISIS KELAYAKAN PEMBERIAN MODAL MENGGUNAKAN METODE Z-SCORE
}

\author{
Aries Maesya ${ }^{1}$, Evi Sopiani ${ }^{2}$ \\ 1,2Universitas Pakuan, Bogor, Indonesia \\ Email korespondensi: ${ }^{1}$ a.maesya@unpak.ac.id
}

\begin{abstract}
ABSTRAK
Tujuan penelitian ini adalah menilai kesehatan keuangan mitra menggunakan metode Z-Score untuk memprediksi kesehatan keuangan mitra atau calon debitur. Subjek penelitian ini di tiga mitra atau nasabah dari PT Mitra Bisnis Keluarga Ventura dari sektor manufaktur dan perdagangan. Penelitian ini adalah penelitian kualitatif deskriptif. Metode analisis data menggunakan model Altman Z-Score dengan menganalisis laporan keuangan nasabah PT Mitra Bisnis Keluarga Ventura dari tiga periode atau lebih. Berdasarkan hasil penelitian yang dilakukan, Data Mitra A dikategorikan sehat dengan Z-Score 3,80, Data Mitra B dikatakan tidak sehat dengan nilai 0,52 dan Data Mitra C dikatakan Grey Area karena memiliki angka di bawah 2,60, yaitu 2,33. Hasil penelitian ini mengimplikasikan bahwa Keterkaitan antara Metode Z-Score dengan hasil keputusan tingkat kesehatan keuangan cukup membantu dalam menganalisis laporan keuangan dan dapat menghasilkan keputusan yang tepat dalam menilai kesehatan keuangan mitra.
\end{abstract}

Kata kunci: kebangkrutan; kesehatan keuangan; model Z-Score; rasio keuangan

\section{ABSTRACT}

The purpose of this study is to assess the financial health of partners using the Z-Score method to predict the financial health of partners or prospective debtors. The subjects of this study were three partners of PT Mitra Bisnis Keluarga Ventura from the manufacturing and trading sectors. This research is a descriptive qualitative research. The data analysis method uses the Altman Z-Score model by analyzing the financial statements of PT Mitra Bisnis Keluarga Ventura customers from three or more periods. Based on the results of the research conducted, Partner A's data is categorized as healthy with a Z-Score of 3.80, Mitra B's data is said to be unhealthy with a value of 0.52 and Partner C's data is said to be gray area because it has a number below 2.60, which is 2.33. The results of this study imply that the relationship between the Z-Score method and the results of financial soundness decisions is quite helpful in analyzing financial statements and can produce the right decisions in assessing the financial health of partners.

Keywords: bankruptcy; financial health; financial ratio; Z-Score model

KETERANGAN ARTIKEL

Riwayat Artikel: diterima: 20 September 2021; direvisi:18 Desember 2021; disetujui: 24 Desember 2021

Klasifikasi JEL: B26, G32.

Cara mensitasi: Maesya, A., \& Sopiyani, E. (2021). Menilai Kesehatan Keuangan Mitra dalam Analisis Kelayakan Pemberian Modal Menggunakan Metode Z-Score. JIMFE (Jurnal IImiah Manajemen Fakultas Ekonomi), 7(2), 245254. https://doi.org/ 10.34203/jimfe.v7i2.3945.

\section{PENDAHULUAN}

Pemberian pembiayaan atau modal pinjaman bagi para pengusaha sangat membantu dalam perluasan usaha, khususnya kepada usaha mikro yang memiliki permasalahan kekurangan modal untuk memulai produksi sendiri. PT Mitra Bisnis Keluarga Ventura (MBK) adalah Perusahaan Modal Ventura (PMV) yang diawasi oleh Otoritas Jasa Keuangan (OJK). Dalam pemberian modal usaha menggunakan metodologi 
Grameen Bank, yaitu MBK menyediakan modal kerja dalam bentuk pinjaman yang ditujukan kepada perempuan dari keluarga berpendapatan rendah, dengan tujuan memberikan mereka akses kepada layanan keuangan formal (financial inclusion) (MBK Ventura, 2020). Grameen Bank merancang kredit mikro berbasis kepercayaan bukan kontrak legal dan tanpa adanya jaminan (Fuddin, 2011). Maka penting adanya analisis terhadap sistem keuangan mitra untuk mengetahui kemampuan membayar calon nasabah dalam pengembalian dana, untuk menghindari pembayaran macet. Dengan adanya sistem yang akan dibangun memudahkan perusahaan dalam menentukan kelayakan bagi para debitur yang menerima pinjaman modal. Hal terpenting yang harus diperhatikan oleh perusahaan dalam pemberian modal adalah mengurangi risiko dalam pemberian kredit. Dengan cara meninjau data-data calon anggota sebagai syarat pemberian modal, salah satu data yang sangat penting dari calon anggota adalah laporan keuangan.

Salah satu upaya untuk menghindari kebangkrutan adalah dengan menganalisis kesehatan keuangan perusahaan atau melakukan prediksi potensi kebangkrutan perusahaan melalui laporan keuangan perusahaan (Intansari dkk., 2020). Pengukuran tingkat kesehatan pada calon anggota merupakan sebuah jalan untuk menilai kelayakan pemberian modal kepada mitra yang akan dibiayai. Penilaian Kesehatan keuangan yang dilihat adalah laporan keuangan usaha mitra, apakah kondisi tersebut dalam keadaan sehat atau tidak berdasarkan klasifikasi nilai Z-Score. Menganalisis kinerja mitra apakah layak atau tidak sesuai nilai kelayakan yang telah ditentukan oleh perusahaan. Salah satu studi tentang prediksi ini adalah multiple discriminan analysis (MDA) yang biasa disebut metode Z-Score model Altman. Hal tersebut dapat membantu perusahaan dalam menjaga kondisi kesehatan keuangan di masa yang akan datang. Hal ini bertujuan agar para pemimpin usaha mempunyai kepentingan untuk dapat menyusun, mengembangkan, mempertimbangkan serta menentukan segala keputusan yang tepat agar terhindar dari kebangkrutan.

Beberapa penelitian yang sudah dilakukan diantaranya Haryetti (2010) pada penelitian yang dilakukan bertujuan untuk mengetahui prospek kehidupan dan kemungkinan kebangkrutan industri perbankan yang terdaftar di BEI dilihat dari aspek financial distress. Dari penelitian ini dapat diambil kesimpulan bahwa dari pendekatan financial distress yang dilakukan melalui CAMEL+G (Capital, Asset, Earning, Liquidity, and Growth), EVA (Economic Value Added), dan PSA (Profit Sensitivity Analysis) dengan perhitungan rasiorasio keuangan sepuluh perusahaan sampel diketahui bahwa $60 \%$ bank-bank yang menjadi sampel tersebut berada dalam kondisi aman dari financial distress, sementara $40 \%$ memiliki risiko akan mengalami financial distress, hal ini membuktikan bahwa dengan modal yang besar tidak dapat menjamin perusahaan terhindar dari risiko kebangkrutan.

Mulatsih (2016) melakukan penelitian terhadap perusahaan manufaktur yang bergerak dalam sektor industri otomotif di Bursa Efek Indonesia. Dari keseluruhan nilai Indeks Z-Score dari tahun 2011 sampai dengan tahun 2013 menunjukan nilai dibawah titik cut off Altman Z-Score 2,99, bahkan pada tahun 2013 perusahaan berada dibawah 1,81. Nilai rating perusahaan yang rendah dikarenakan nilai ZScore yang rendah. Hasil penelitian menunjukan secara keseluruhan perusahaan dalam keadaan kurang sehat pada prediksi Z-Score tahun 2011 dan 2012 dan tidak sehat pada tahun 2013.

Astuty (2018) pada penelitiannya bertujuan untuk mendapatkan bukti data prediksi kesulitan keuangan dan kebangkrutan menggunakan metode Z-Score pada perusahaan Paper dan Allied Products yang terdaftar di Bursa Efek Indonesia. Hasil penelitian ini dapat disimpulkan kinerja keuangan perusahaan Paper dan Allied Products yang terdaftar di BEI, menunjukan nilai Z-Score terjadi di beberapa perusahaan tersebut disebabkan karena adanya penurunan laba, peningkatan biaya dan turunnya harga saham perusahaan. Berdasarkan uraian diatas, bahwa kesehatan keuangan adalah landasan utama terlaksananya semua program perusahaan. Maka pada penelitian ini akan menganalisis tingkat kesehatan keuangan mitra atau calon debitur menggunakan Metode Z-Score. 


\section{KAJIAN LITERATUR DAN PENGEMBANGAN HIPOTESIS Kesehatan Keuangan}

Kesehatan keuangan merupakan terlaksananya semua program pengajuan mitra terhadap pinjaman tersebut, di mana keuangan mitra dinilai agar menemukan hasil sehat atautidak suatu keuangan menurut standar atau kriteria penetapan tingkat kesehatan perusahaanitu sendiri. Hal ini dapat dilakukan dengan membandingkan antara dua elemen yang ada atau disebut dengan rasio. Dengan rasio tersebut dapat mengetahui tingkat rentabilitas, likuiditas, dan solvabilitas suatu usaha mitra dalam suatu periode tertentu (Harahap, 2013). Kesulitan usaha merupakan kondisi kontinum, dari kesulitan keuangan yang ringan (seperti masalah likuiditas) sampai pada kesulitan yang lebih serius, yaitu tidak solvabel (utang lebih besar dibandingkan dengan aset). Pada kondisi ini perusahaan praktis bisa diakatakan sudah bangkrut (Hanafi, 2010).

Kegagalan dalam arti ekonomis bahwa pendapatan perusahaan tidak mampu lagi menutup biayanya, yang berarti bahwa tingkat labanya lebih kecil daripada biaya modalnya. Kegagalan keuangan (financial distressed) insolvensi memiliki dua bentuk, yakni default teknis yang terjadi bila suatu perusahaan gagal memenuhi salah satu atau lebih kondisi didalam ketentuan hutangnya, seperti rasio aktiva lancar dengan hutang lancar yang ditetapkan, serta kegagalan keuangan atau ketidakmampuan teknik (technical insolvency) yang terjadi apabila perusahaan tidak mampu memenuhi kewajibannya pada waktu yang telah ditentukan walaupun harta totalnya melebihi hutangnya. Pada situasi tertentu, perusahaan mungkin akan mengalami kesulitan keuangan (Tambunan, 2015). Jika tidak diselesaikan dengan benar, kesulitan keuangan kecil dapat berkembang menjadi lebih besar dan akan sampai pada kebangkrutan. Ada dua penyebab kegagalan perusahaan, yaitu dalam segi ekonomi dan segi keuangan, dari kekurangan pengalaman manajerial sampai kekurangan modal. Ada beberapa alternatif untuk menyelesaikan kesulitan usaha seperti restrukturisasi atau reorganisasi dan likuidasi.

\section{Prediksi Kebangkrutan dengan Altman Z-Score Model}

Prediksi kebangkrutan berfungsi untuk memberikan panduan bagi pihak-pihak tentang kinerja keuangan perusahaan apakah akan mengalami kesulitan keuangan atau tidak dimasa mendatang. Prediksi kesulitan keuangan ini salah satunya dikemukakan oleh seorang profesor dari New York University bernama Edward Altman, dengan Altman Z-Score (Goswami, 2014). Rumus ini merupakan hasil penelitian yang dilakukannya terhadap perusahaan-perusahaan yang mengalami kebangkrutan di Amerika Serikat. Rasio-rasio yang digunakan untuk memprediksi kebangkrutan adalah rasio likuiditas, rasio aktivitas, rasio profitabilitas, dan rasio nilai pasar. Komponen-komponen yang ada pada Altman ZScore adalah modal kerja, aktiva, modal sebelum pajak, laba ditahan, penjualan dan nilai pasar ekuitas (Darsono \& Ashari, 2005). Analisis Z-Score merupakan analisis yang dapat digunakan untuk mengetahui adanya tanda-tanda atau gejala tidak sehatnya perusahaan (Riesmiyantiningtias, 2021).

Dengan analisis Z-Score, manajemen dapat memprediksi bagaimana prospek perusahaan pada masa mendatang dalam menjaga kelangsungan hidupnya. Makin besar nilai Z, maka makin besar kelangsungan hidup perusahaan dan risiko kegagalan akan makin berkurang (Khamidah, 2012). Analisis Z-Score digunakan untuk memprediksi kebangkrutan perusahaan. Selain itu, analisis kebangkrutan bermanfaat karena bisa membuat perusahaan melakukan antisipasi yang diperlukan. Metode Z-Score adalah model untuk memprediksi kebangkrutan suatu perusahaan dengan mengkombinasikan beberapa rasio keuangan yang umum dan pemberian bobot yang berbeda satu dengan lainnya. Z-Score dikembangkan oleh Edward I Altman yang merupakan orang pertama dengan sukses menggunakan step-wise multiple discriminate analysis, untuk mengembangkan suatu model prediksi (Rudianto, 2013). 
Aries Maesya: Menilai Kesehatan Keuangan...

Rumus Altman Z-Score dibedakan menjadi dua, yaitu untuk perusahaan manufaktur dan perusahaan nonmanufaktur. Hal ini karena output produk perusahaan manufaktur dan nonmanufaktur berbeda. Formula Z-Score pada perusahaan manufaktur adalah sebagai berikut.

$$
\mathrm{Z}-\text { Score }=1,2 \mathrm{X} 1+1,4 \mathrm{X} 2+3,3 \mathrm{X} 3+0,6 \mathrm{X} 4+1,0 \mathrm{X} 5
$$

Selain itu, untuk formula Z-Score pada perusahaan nonmanufaktur adalah sebagai berikut.

$$
\mathrm{Z}-\text { Score }=6,56 \mathrm{X} 1+3,26 \mathrm{X} 2+6,72 \mathrm{X} 3+1,05 \mathrm{X} 4
$$

Dengan $\mathrm{Z}$ adalah bankcruptcy index; $\mathrm{X} 1$ adalah working capital to total asset; $\mathrm{X} 2$ adalah retained earning to total assets; $\mathrm{X} 3$ adalah earnings before ilnterest and taxes to total assets (EBIT); X4 adalah market value of equity to book value of total debt; X5 adalah sales to total assets. Rumus X5 (asset turnover) pada perusahaan nonmanufaktur dihilangkan karena perputaran aset pada perusahaan nonmanufaktur (seperti perusahaan jasa) tidak memiliki pengaruh yang berarti dibandingkan perusahaan manufaktur (Panigrahi, 2019).

Tabel 1. Kriteria Penilaian Altman Z-Score

\begin{tabular}{lcc}
\hline \multicolumn{1}{c}{ Kategori } & Manufaktur & Non Manufaktur \\
\hline Sehat & $>2,99$ & $>2,60$ \\
Grey Area & $>1,80$ & $>1,1$ \\
Bangkrut & $<1,80$ & $>1,1$ \\
\hline
\end{tabular}

\section{METODE PENELITIAN}

Penelitian ini adalah penelitian kualitatif dengan metode analisis data menggunakan perhitungan model Z-Score. Subjek penelitian ini adalah calon debitur PT Mitra Bisnis Keluarga Ventura dari tiga sampel jenis usaha, yaitu pabrik sepatu, pakaian, dan warung sembako. Data penelitian berupa data sekunder berupa laporan keuangan calon debitur tersebut dari periode 2019 sampai 2020 dan periode 2018 sampai 2020. Metode analisis data menggunakan analisis Z-Score untuk mengukur kesehatan keuangan mitra dan analisis system development life cycle (SDLC). Penelitian ini dilakukan untuk menentukan kelayakan mitra yang akan diberikan pinjaman dengan beberapa parameter kelayakan. Pertama, data yang diinput adalah data mitra beserta laporan keuangannya setelah itu sistem menilai kelayakan yang sesuai dengan indikator kelayakan tersebut. Kelayakan mitra diukur berdasarkan pendapatan, pengeluaran, pinjaman angsuran, dan skor rumah menggunakan parameter kelayakan sebagai berikut.

Tabel 2. Parameter Kelayakan

\begin{tabular}{clcc}
\hline No. & \multicolumn{1}{c}{ Parameter } & Nilai & Kelayakan \\
\hline 1 & Pendapatan & $>50 \%$ & Layak \\
2 & Pengeluaran & $>50 \%$ & Tidak Layak \\
3 & Pinjaman Angsuran & $>3$ lembaga & Tidak Layak \\
4 & Skor Rumah & $>15$ & Tidak Layak \\
\hline
\end{tabular}

Untuk mengukur kelayakan berikut formula perhitungan Z-Score.

$$
Z \text { Score }=X 1+X 2+X 3+X 4+X 5
$$


$X_{1}$ adalah working capital to total assets ratio, $X_{2}$ adalah rentained earnings in total assets ratio $X_{3}$ adalah earning before interest and taxes to total asset ratio, $X_{4}$ adalah market value of equity to book value of total debt, $X_{5}$ adalah sales to total assets.

\section{HASIL DAN PEMBAHASAN}

\section{Working Capital to Total Assets Ratio (X1)}

Rasio working capital to total assets (WCTA) merupakan rasio yang menunjukkan perbandingan modal kerja (aktiva lancar-hutang lancar) dengan total aset (Riyanto, 2001). WCTA masing-masing mitra dihitung menggunakan formula berikut.

$$
W T C A=\frac{\text { working capital }}{\text { Total Aset }}
$$

Tabel 3 menunjukkan nilai WCTA masing-masing mitra yang menjadi objek penelitian.

Tabel 3. Working Capital to Total Assets Ratio

\begin{tabular}{ccrcc}
\hline Mitra & Tahun & Working Capital & Total Aset & X1 \\
\hline \multirow{2}{*}{ A } & 2019 & 10.500 .000 & 76.840 .000 & 0,100 \\
& 2020 & 11.140 .000 & 87.416 .700 & 0,100 \\
B & 2019 & 600.000 & 38.000 .000 & 0,000 \\
& 2020 & 900.000 & 34.700 .000 & 0,000 \\
& 2018 & 18.137 .000 & 87.427 .000 & 0,200 \\
C & 2019 & 17.389 .700 & 71.014 .700 & 0,200 \\
& 2020 & 13.571 .900 & 47.650 .900 & 0,300 \\
\hline
\end{tabular}

Modal kerja merupakan asset lancar dikurangi kewajiban lancar yang dibagi dengan total aset. $\mathrm{Di}$ Tabel 3 menunjukkan bahwa nilai rasio working capital dibandingkan dengan aset pada Mitra A sebesar $10 \%$ pada dua tahun penelitian. Nilai ini menunjukkan setiap satu rupiah aset yang dimiliki Mitra A di dalamnya terdapat $10 \%$ modal kerja. Pada Mitra B menunjukkan nilai working capital nilai 0,00\% yang menunjukkan rendahnya modal kerja. Hal ini harus menjadi perhatian perusahaan karena modal kerja yang cukup dapat memastikan lancarnya kegiatan operasional perusahaan. Rendahnya nilai modal kerja dapat mengganggu kegiatan operasional perusahaan. Pada Mitra $\mathrm{C}$ menunjukkan nilai modal kerja yang meningkat pada tahun 2020 , yaitu dari sebelumnya $20 \%$ menjadi $30 \%$.

\section{Retained Earnings to Total Assets Ratio (X2)}

Retained earnings to total assets merupakan rasio untuk mengukur kemampuan perusahaan untuk menghasilkan laba ditahan dari total aset perusahaan. Retained earnings to total assets ratio diukur menggunakan formula berikut.

$$
\text { RETA }=\frac{\text { Retained Earning }}{\text { Total Aset }}
$$

Tabel berikut menunjukkan nilai retained earnings to total assets ratio masing-masing mitra yang menjadi subjek penelitian. 
Aries Maesya: Menilai Kesehatan Keuangan...

Tabel 4. Retained Earning to Asset Ratio

\begin{tabular}{ccrcc}
\hline Mitra & Tahun & Retained Earning & Total Aset & X1 \\
\hline \multirow{2}{*}{ A } & 2019 & 11.940 .000 & 76.840 .000 & 0,200 \\
& 2020 & 9.035 .000 & 87.416 .700 & 0,100 \\
B & 2019 & 570.000 & 38.000 .000 & 0,000 \\
& 2020 & 1.053 .000 & 34.700 .000 & 0,000 \\
& 2018 & 4.842 .500 & 87.427 .000 & 0,100 \\
C & 2019 & 9.235 .500 & 71.014 .700 & 0,100 \\
& 2020 & 24.932 .000 & 47.650 .900 & 0,500 \\
\hline
\end{tabular}

Hasil pengukuran menunjukkan bahwa pada Mitra A dapat menghasilkan laba ditahan sebesar $20 \%$ dari total asetnya pada tahun 2019 dan menurun pada tahun 2020 sebesar 10\%. Pada Mitra B hasil pengukuran menunjukkan nilai $0,00 \%$ yang mengindikasikan bahwa perusahaan tidak memiliki laba ditahan karena seluruh laba diputar kembali untuk operasional atau dibagikan kepada pemilik. Pada Mitra C nilai laba ditahan sebesar $10 \%$ dari penggunaan asetnya dan meningkat pada tahun 2020 sebesar $50 \%$. Makin besar nilai rasio menunjukkan makin besar laba ditahan yang dimiliki perusahaan.

\section{Earning Before Interest and Taxes to Total Assets Ratio (EBIT) (X3)}

Rasio ini berguna untuk mengukur profitabilitas suatu bisnis tanpa memandang seberapabesar utang dari perusahaan tersebut. Rasio ini mewakili rasio profitabilitas, hasil perhitungan ditunjukan pada Tabel 3.

$$
X 3=\frac{E B I T}{\text { Total Aset }}
$$

Tabel 5 menunjukkan hasil pengukuran rasio laba sebelum bunga dan pajak dengan total aset.

Tabel 5. Earning Before Interest and Taxes to Total Assets Ratio

\begin{tabular}{ccrrc}
\hline Mitra & Tahun & Retained Earning & Total Aset & X1 \\
\hline \multirow{2}{*}{ A } & 2019 & 19.560 .000 & 76.840 .000 & 0,300 \\
& 2020 & 18.055 .000 & 87.416 .700 & 0,200 \\
B & 2019 & 15.180 .000 & 38.000 .000 & 0,400 \\
& 2020 & 13.174 .500 & 34.700 .000 & 0,400 \\
& 2018 & 19.780 .000 & 87.427 .000 & 0,200 \\
C & 2019 & 18.064 .500 & 71.014 .700 & 0,300 \\
& 2020 & 16.543 .000 & 47.650 .900 & 0,300 \\
\hline
\end{tabular}

Hasil penelitian menunjukkan bahwa Mitra A menghasilkan laba sebesar 30\% dari penggunaan total asetnya dan menurun pada tahun 2020 sebesar 20\%. Mitra B menghaislkan laba lebih besar dibandingkan Mitra A sebesar 40\% pada tahun 2019 dan 2020. Pada Mitra C nilai rasio laba operasi terhadap total aset menunjukkan nilai 30\% pada tahun 2019 dan 2020 yang berarti menghasilkan laba sebesar $30 \%$ dari penggunaan asetnya. Rata-rata rasio menunjukkan nilai yang stabil pada seluruh mitra.

\section{Market Value of Equity to Book Value of Total Debt (X4)}

Rasio ini mengukur kemampuan perusahaan dalam memberikan jaminan kepada setiap utangnya melalui modalnya sendiri. Berikut adalah formula untuk mengukur market value of equity to book value of total debt. 


$$
X 4=\frac{\text { Nilai Ekuitas }}{\text { Total Liabilitas }}
$$

Tabel 6 menunjukkan nilai rasio dari ekuitas terhadap total liabilitas perusahaan pada tiga mitra yang menjadi objek penelitian.

Tabel 6. Market Value of Equity to Book Value of total debt

\begin{tabular}{ccrrc}
\hline Mitra & Tahun & Retained Earning & Total Liabilitas & X1 \\
\hline \multirow{2}{*}{ A } & 2019 & 64.740 .000 & 12.100 .000 & 5,400 \\
& 2020 & 75.966 .700 & 11.450 .000 & 6,600 \\
B & 2019 & 24.100 .000 & 13.900 .000 & 1,700 \\
& 2020 & 24.400 .000 & 10.300 .000 & 2,400 \\
& 2018 & 70.487 .000 & 16.940 .000 & 4,200 \\
C & 2019 & 53.314 .700 & 15.700 .000 & 3,500 \\
& 2020 & 35.496 .900 & 12.154 .000 & 2,900 \\
\hline
\end{tabular}

Di perusahaan ini memiliki ekuitas jauh lebih besar dibandingkan dengan utang, cukup baik untuk kelangsungan sebuah perusahaan. Mitra A menunjukkan nilai 5,400 yang berarti nilai ekuitas sebesar 5,400 kali dibanting liabilitasnya. Nilai rasio meningkat pada tahun 2020 yang mungkin mengindikasikan menurunnya nilai liabilitas. Mitra B menunjukkan nilai 1,700 pada tahun 2019 dan 4,200 pada tahun 2020. Pada Mitra C nilai rasio terus mengalami penurunan dari tahun 2018 sampai 2020. Hal ini mengindikasikan makin besarnya hutang atau menurunnya nilai ekuitas perusahaan.

\section{Sales to total Asset (X5)}

Penjualan terhadap total asset digunakan untuk mengukur kemampuan manajemen dalam menghadapi kondisi persaingan. Rasio sales to total aset diukur menggunakan formula berikut.

$$
X 3=\frac{\text { Sales }}{\text { Total Aset }}
$$

Tabel 7 menunjukkan hasil pengukuran sales to total asset dari masing-masing mitra.

Tabel 7. Sales to Total Asset

\begin{tabular}{ccccc}
\hline Mitra & Tahun & \multicolumn{1}{c}{ Sales } & Total Aset & X1 \\
\hline \multirow{2}{*}{ A } & 2019 & 25.000 .000 & 76.840 .000 & 5,400 \\
& 2020 & 17.500 .000 & 87.416 .700 & 6,600 \\
B & 2019 & 7.210 .000 & 38.000 .000 & 1,700 \\
& 2020 & 9.800 .000 & 34.700 .000 & 2,400 \\
& 2018 & 22.500 .000 & 87.427 .000 & 4,200 \\
C & 2019 & 21.100 .000 & 71.014 .700 & 3,500 \\
& 2020 & 29.350 .000 & 47.650 .900 & 2,900 \\
\hline
\end{tabular}

Hasil penelitian menunjukkan nilai rasio sales to total asset sebesar 5,400 yang berarti perputaran asetnya sebsar 5,400 kali dan meningkat pada tahun 2020. Hal ini menunjukkan bahwa perusahaan makin efisien menggunakan asetnya untuk menghasilkan pendapatan. Begitu pula dengan Mitra $B$ yang rasionya mengalami peningkatan yang menunjukkan makin efektif pemanfaatan aset perusahaan untuk 
Aries Maesya: Menilai Kesehatan Keuangan...

menghasilkan pendapatan. Namun, pada Mitra $\mathrm{C}$ mengalami penurunan rasio yang berarti perusahaan kurang efisien dalam menggunakan asetnya.

\section{Seleksi Data Z-Score}

Hasil perhitungan metode Z-Score yang digunakan sebagai alat ukur untuk menilai kondisi keuangan perusahaan. Berikut adalah tabel ringkasan untuk penilaian menggunakan Altman Z-Score dengan formula sebagai berikut.

Tabel 8. Hasil Penilaian Z-Score

\begin{tabular}{|c|c|c|c|c|}
\hline \multicolumn{5}{|c|}{ Altman Z-Score } \\
\hline \multicolumn{2}{|c|}{ Koefisien } & Mitra A & Mitra B & Mitra C \\
\hline $\mathrm{X1}$ & 1,2 & 0,15 & 0,03 & 0,25 \\
\hline$x 2$ & 1,4 & 0,14 & 0,04 & 0,08 \\
\hline$x 3$ & 3,3 & $-0,68$ & $-1,25$ & $-0,75$ \\
\hline$x 4$ & 0,6 & 3,98 & 1,42 & 2,50 \\
\hline X5 & 1,0 & 0,20 & 0,28 & 0,26 \\
\hline \multicolumn{2}{|c|}{ Z-Score } & 3,80 & 0,52 & 2,33 \\
\hline \multicolumn{2}{|c|}{ Result } & Sehat & Tidak Sehat & Grey Area \\
\hline
\end{tabular}

$Z$ Score $=1,2 X 1+1,4 X 2+3,3 X 3+0,6 X 4+1,0 X 5$

Dengan titik cut-off sebagai berikut: $Z<1,81=$ Perusahaan potensial bangkrut $1,81 \leq Z \leq 2,99=$ Perusahaan grey-area (dalam kondisi rawan bangkrut) $Z>2,99=$ Perusahaan dalam kondisi sehat maka hasil analisis menunjukkan Mitra A ada pada kondisi sehat, Mitra B dalam kondisi tidak sehat, dan C ada pada kondisi grey area atau pada kondisi rawan bangkrut. Dengan demikian, Mitra A dapat memperoleh modal dari kreditur. Mitra B tidak masuk kriteria dalam memperoleh pinjaman karena nilai Altman ZScore ada di bawah 1,81. Hal ini mengindikasikan dari nilai modal kerja yang kecil, laba ditahan yang sangat kecil, kemampuan menghasilkan labanya kecil, serta perputaran aset yang rendah. Pada Mitra $\mathrm{C}$ yang ada pada grey area atau rawan bangkrut masih dapat menerima pinjaman.

\section{Uji Kelayakan Mitra}

Kelayakan pemberian modal memiliki beberapa indikator di setiap dimensi. Dalam penentuan pemberian modal dapat ditentukan klasifikasi, kelompok, dan skor sesuai dengan ketentuan yang berlaku di perusahaan tersebut. Selain perhitungan sebelumnya, analisis kelayakan pemberian modal dapat dinilai seperti pada tabel berikut.

Tabel 9. Hasil Kelayakan Mitra

\begin{tabular}{lcccccc}
\hline \multirow{2}{*}{ Kategori } & \multicolumn{2}{c}{ Mitra A } & \multicolumn{2}{c}{ Mitra B } & \multicolumn{2}{c}{ Mitra C } \\
\cline { 2 - 7 } & Hasil & Kelayakan & Hasil & Kelayakan & Hasil & Kelayakan \\
\hline Pendapatan & $68 \%$ & Layak & $72 \%$ & Layak & $74 \%$ & Layak \\
Pengeluaran & $48 \%$ & Layak & $56 \%$ & tidak layak & $47 \%$ & Layak \\
Pinjaman & - & Layak & $>3$ & tidak layak & $<3$ & Layak \\
Skor Rumah & 13 & Layak & 10 & Layak & 11 & Layak \\
\hline
\end{tabular}


Pinjaman atau pemberian modal dapat diberikan ketika seluruh kategori ada pada kondisi layak. Sejalan dengan analisis Z-Score makan Mitra A dan C ada pada konsisi layak dalam semua kategori dengan demikian MItra A dan C dapat menerima pinjaman. Walaupun nilai Z-Score ada pada grey area, berdasarkan empat kategori kelayakan, Mitra $\mathrm{C}$ memenuhi syarat kelayakan. Mitra B sesuai juga dengan perhitungan Z-Score yang menunjukkan hasil kelayakan hanya memenuhi syarat pada kategori pendapatan dan skor rumah. Kategori pengeluaran dan pinjaman tidak memenuhi syarat kelayakan. Dengan demikian, Mitra B tidak dapat menerima pinjaman.

\section{KESIMPULAN}

Sistem yang dibangun adalah menilai kelayakan usaha mitra dan keuangannya untuk menentukan calon peminjam pantas atau tidak dalam pemberian modal tersebut. Data yang sudah diolah disesuaikan dengan ketentuan klasifikasi Z-Score dan diterapkan pada sistem yang berjalan. Berdasarkan peraturan perusahaan jika semua kategori kelayakan hasilnya layak dan sesuai dengan ketentuan, calon mitra dapat diberikan pinjaman sesuai rasio keuangannya masing-masing. Sistem pendukung keputusan dalam menilai keuangan mitra dengan menggunakan Z-Score dapat disimpulkan layak dan sehat dari segi keuangan, dapat dilanjutkan dengan tahap pencairan sesuai dengan kemampuan rasio mitra. Keterkaitan antara Metode Z-Score dengan hasil keputusan tingkat kesehatan keuangan cukup membantu dalam menganalisis laporan keuangan dan dapat menghasilkan keputusan yang tepat dalam menilai kesehatan keuangan mitra. Sistem pendukung keputusan ini perlu dilengkapi dengan metode lain, untuk melakukan perbandingan antara metode Z-Score dengan metode lainnya. Data harus lebih banyak diolah lagi agar tidak terjadi kesalahan dalam setiap perbandingan.

\section{DAFTAR PUSTAKA}

Astuty, W. (2018). Analisis Tingkat Kesehatan Menggunakan Metode Z-Score Pada Perusahaan Manufaktur yang terdaftar di Bursa Efek Indonesia. Jurnal IImiah Manajemen dan Bisnis, 10(1), 96-115.

Darsono, \& Ashari. (2005). Pedoman Praktis Memahami Laporan Keuangan. Yogyakarta: CV Andi Offset.

Fuddin, M. K. (2011). Pemberantas Kemiskinan Dan Kecukupan Modal Di Dua Dimensi Berbeda Melalui Model Apex BPR Dan Grameen Bank. Jurnal Ekonomi Pembangunan, 9(2), 243-265.

Goswami, S., Chandra, B., \& Chouhan, V. (2014). Predicting Financial Stability Of Select BSE Companies Revisiting Altman Z-Score. International Letters of Social and Humanistic Sciences, 15(1), 92-105. https://doi.org/10.18052/www.scipress.com/ILSHS.26.92

Hanafi, M. M. (2010). Manajemen Keuangan. Yogyakarta: BPFE.

Harahap, Sofyan Syafri. (2013). Analisa Kritis atas Laporan Keuangan. Jakarta: PT Raja Grafindo Persada. Haryetti. (2010). Analisis Financial Distress untuk Memprediksi Risiko Kebangkrutan Perusahaan (Studi Kasus pada Industri Perbankan di BEI). Jurnal Ekonomi, 18(2), 23-35. http://dx.doi.org/10.31258/je.18.02.p.\%25p

Intansari, D., Kristanti, F., Atahau, A. D. R., \& Sakti, I. M. (2020). Analisis Kesehatan Keuangan PT Pembangunan Jaya Ancol Tbk Menggunakan Model Analisis Altman Z-Score. Jurnal Pamator: $\begin{array}{llll}\text { Jurnal Ulmiah Universitas } & \text { 206-212. }\end{array}$ https://doi.org/10.21107/pamator.v13i2.8083

Khamidah, F, N. \& Afandi, S. P. (2012). Analisis Tingkat Kesehatan Keuangan Pada Perusahaan Semen Go Public Di Bursa Efek Indonesia. Among Makarti: Journal of Economic and Business, 5(9), 55-75. http://dx.doi.org/10.52353/ama.v5i1.67

Mulatsih, R. M. (2016). Analisis Potensi Kebangkrutan Perusahaan dengan menggunakan metode Altman Z-Score pada PT Gajah Tunggal, Tbk. Tahun 2011-2013. Universitas Gunadarma Journal, 
9(9), 14-17.

Panigrahi, A. (2019). Validity of Altman's ' $Z$ ' Score Model in Predicting Financial Distress of Pharmaceutical Companies. Journal Of Economics And Public Policy, 4(1), 65-73

PT MBK Ventura. (2020). Laporan Keuangan Berkelanjutan 2020. https://www.mbkventura.com/images/MBK_\%20LAPORAN\%20AKSI\%20KEUANGAN\%20BERKELANJUTAN\%20TAHU N\%202020.pdf

Riyanto, B. (2014). Rasio Keuangan Likuiditas. Yogyakarta: BPFE

Riesmiyantiningtias, N. (2021). Analisis Kesehatan Keuangan Dengan Metode Altman Z - Score Pada PT Matahari Department Store Tbk. Jurnal AKRAB JUARA, 6(2), 106-114.

Rudianto. (2013). Akuntansi Manajemen Informasi untuk Pengambilan Keputusan Strategis. Jakarta: Erlangga.

Tambunan, R. W., Dwiatmanto, \& Endang, M. G. (2015). Analisis Prediksi Kebangkrutan Perusahaan Dengan Menggunakan Metode Altman (Z-Score) (Studi Pada Subsektor Rokok Yang Listing Dan Perusahaan Delisting Di Bursa Efek Indonesia Tahun 2009 - 2013). Jurnal Administrasi Bisnis (JAB), 2(1), 1-11. 